\title{
Üniversite Spor Takımlarında Oynayan Öğrencilerin Anksiyete ve Spora Özgü Başarı Motivasyonu Düzeylerinin İncelenmesi
}

\begin{abstract}
Sultan YAVUZ EROĞLU*
Özet

Bu çalışmada: Üniversite spor takımlarında oynayan öğrencilerin anksiyete ile sporda başarı motivasyonu düzeylerinin incelenmesi amaçlanmıştır. Araştırmanın evrenini: Ankara, Pamukkale, Siirt ve Iğdır Üniversitesi spor takımlarında oynayan öğrenciler oluşturmaktadır. Araştırmanın örneklemini ise, evrenden rastgele yöntem ile seçilen 134 kadın, 187 erkek toplam 321 öğrenci oluşturmaktadır. Veri toplama aracı olarak, kişisel bilgi formu, Beck Anksiyete Ölçeği ve Willis Spora Özgü Başarı Motivasyonu Ölçeği kullanılmıştır. Verilerin analizi aşamasında analizler öncesinde verinin normal dağılıp dağılmadığı kontrol edilmiş ve KolmogorowSmirnov normallik testi sonucunda verinin normallik varsayımını karşıladığı belirlenmiştir $(p>0,05)$. İkili karşılaştırmaların tespiti için T-testi ikiden fazla bağımsız değişkenler ile bağımlı değişkenler arasındaki farkın tespiti için One-Way Anova testi kullanılmıştır. Ölçeklerin alt boyutları arasındaki ilişkinin tespiti için pearson korelasyon analizi kullanılmıştır. Sonuç olarak: Öğrencilerin Anksiyete Ölçeği alt boyutları ve Spora Özgü Başarı Motivasyonu Ölçeği alt boyutlarında cinsiyet, bölüm ve okul değişkenlerine göre anlamlı farklılık görülmüştür $(p<0,05)$. Ancak sınıf değişkenine göre anlamlı farklılık görülmemiş̧tir $(p>0,05)$. Anksiyete Ölçeği alt boyutu ile Spora Özgü Başarı Motivasyonu Ölçeği alt boyutları arasında düşük düzeyde pozitif ve anlamlı ilişki olduğu görülmüştür ( $\mathrm{p}>0,05)$.
\end{abstract}

Anahtar Kelimeler: Sporcu, Anksiyete, Motivasyon, Sporda Başarı Motivasyonu

\section{Anxiety and Sports-Specific Achievement Motivation Levels of Students Playing in University Sports Teams}

\begin{abstract}
In this study: The aim of this study was to investigate the anxiety and success motivation levels of the students who play in university sports teams. The universe of the research consists of students playing sports in Ankara, Pamukkale, Siirt and Iğdır University sports teams. The sample of the study consists of 321 female and 187 male students, randomly selected from the universe. Personal information form, Beck Anxiety Scale and Willis Sports Specific Success Motivation Scale were used as data collection tools. In the analysis of the data, it was checked whether the data was distributed normally before the analyzes and it was determined that the data met the normality assumption as a result of the Kolmogorow-Smirnov normality test ( $p>0.05$ ). One-Way ANOVA test was used to determine the difference between more than two independent variables and dependent variables. Pearson correlation analysis was used to determine the relationship between the sub-dimensions of the scales. As a result: There was a significant difference between the Anxiety Inventory and Sport Specific Motivation Scale subscales of the students according to gender, department and school variables ( $p<0,05$ ). However, there was no significant difference according to the class variable ( $p>0.05$ ). There was a low positive and significant relationship between the Anxiety Scale subscale and the Sports Specific Success Motivation Scale subscales ( $\mathrm{p}>0.05$ ).
\end{abstract}

Keywords - Athlete, Anxiety, Motivation, Motivation of Success in Sports

\footnotetext{
* Dr. Öğr. Üyesi, Siirt Üniversitesi, Beden Eğitimi ve Spor Yüksekokulu, Siirt-Türkiye, sultanyavuzeroglu@ siirt.edu.tr

** Dr. Öğr. Üyesi, Siirt Üniversitesi, Beden Eğitimi ve Spor Yüksekokulu, Siirt-Türkiye, erdemeroglu@ @iirt.edu.tr
} 


\section{GİRIŞ}

Günümüzde duygu ve düşüncelerimizi açık olarak ifade edememek aile, okul, iş gibi ortamlarda yaşanan iletişim kısıtlıkları son yıllarda eğitimcileri ve psikologları sosyal beceriler üzerinde durmaya yöneltmiștir (Reyhan, 2017). Anksiyete bir ifadeyle kaygı olarak adlandirılan duygu durumu, insanlık tarihi boyunca hemen herkesin karşılaştı̆̆ 1 bir duygudur. Öyle ki konuya ilişkin çeşitli betimlemelere antik metinlerde de rastlanmaktadır. Örneğin Hipokrat'ın, ruhsal bozukluklarla ilgili metinlerinde "korkudan" ve "amaçsız anksiyete" (aimless anxiety) olarak adlandırdığı bir durumdan söz ettiği bilinmektedir (Taparlı, 2004). Anksiyete sözcügünün etimolojisine baktığımızda ise Fransızca (anxiété) "sıkıntı, endişe, sebepsiz korku" gibi anlamlarda kullanıldığı, aynı sözcügün Latince (angere, anx-) "sikmak, daraltmak, boğmak" fiilinden türetildiği,Latince fiil olarak Hint Avrupa Anadilinde yazılı örneği bulunmayan (angh) "dar, sıkı" biçiminden evrildiği görülmektedir. (https://www.etimolojiturkce.com/kelime/ank siyete). Anksiyete kavramının tanımı ile ilgili literatürde farklı pek çok tanıma rastlamak mümkündür. $\mathrm{Bu}$ tanımlardan bazıları şu şekildedir;

Anksiyete, tehdit edici ancak belirsiz bir olay karsısındaki gergin bir bekleyiş durumudur (Rachman, 1998). Anksiyete, genellikle bilinmeyen ve anlaşılamayan yakın bir tehlikeyi beklemekte olmanın doğurduğu huzursuzluk ve gerginlik hissidir (Taparl, 2004). Anksiyete, kişiliğin bilinçli tarafi ile duyulan ve kavranılan bir tehlike uyaranıdır (Dubovsky, 1990). Anksiyete, kaynağ 1 belirsiz olan bir çesit korku halidir (Baltas, 1992). Endise, kuruntu, telas, üzüntü gibi insanlarda baskı ve gerilime yol açan duygu durumudur. Mutluluğu tehdit eden gerçek ya da hayali nesnenin yol açtığı gerginlik, huzursuzluk ve korkuyla karakterize olan subjektif bir deneyimdir (Taparl1, 2004). Anksiyete ve stres oluşturan durumların insanda yarattığı olumsuz durumlar üzüntü, olumsuz algilama ve gerginlik gibi hos olmayan, duygusal ve gözlenemeyen tepkilerdir. Bir kisi kaygılandığı zaman merkezi sinir sistemi uyarılır, kalp ve nabız atısları hızlanır ve ellerin titremesi gibi fiziksel reaksiyonlar görülebilir. Kisinin anksiyete düzeyinin yoğunluğu stres yaratan uyarıcının kisi tarafından nasıl algılandığına bağlıdır. Ortaya çıkan durum bireye zarar vermeye, bir tehdit olusturma derecesine göre de anksiyete artacaktır (Turhan, 2009).

Yukarıda yer alan tanımlardan yola çıkarak anskiyeteyi, insanların belirsiz durumlarda, ne gibi sonuçların ortaya çıkacağını bilememesinden kaynaklı, insan zihnini ve duygularını tedirgin eden bir durum olarak tanımlayabiliriz. Bu tür duyguları yaşamak özellikle kazanma durumunun önem arz ettiği spor faaliyetlerinde yer alan sporcular için kaçınılmazdır. Anksiyeteden yani kayg1 durumundan uzaklaşmak sporcuların başarılı olması ve olumlu sonucun ortaya çıkması için son derece gereklidir. $\mathrm{Bu}$ durumdan uzaklaşmak ise hiç şüphesiz motivasyon ile mümkün olabilmektedir.

Motivasyon (güdülenme) temel bir psikolojik süreç olup istekleri, arzuları, ihtiyaçları ve ilgileri kapsayan geniş bir kavramdır (Cüceloğlu, 1991). Genel anlamda motivasyon, insan organizmasını davranışa iten, bu davranışların şiddet ve enerji düzeyini tayin eden, davranışlara belirli bir yön veren ve bunun devamını sağlayan çeşitli iç ve dış sebeplerle birlikte bunların isleyişini kapsayan, hem biyolojik ve fizyolojik hem de kültürel içerikli bir durum olarak tanımlanabilir (Turhan, 2009). Sage'e göre motivasyon, kişinin çabasının (eforunun) yönünü ve yoğunluğunu anlatır. Çabanın yönü; her hangi bir duruma yaklaşmayı veya kaçınmayı ifade ederken, çabanın yoğunluğu bir durumda ne kadarlık eforun harcandığını ifade eder (Tiryaki, 2000). Spor olgusunu sporu yapanlar için kazanmaya yönelik bir çaba olarak düşündügümüzde motivasyon özellikle başarı motivasyonunun spor için ne kadar önemli olduğu da ortaya çıkmaktadır.

Basarı motivasyonu, kisilerin düsünceleri, davranısları ve duyguları üzerinde farklı boyutlarda etki ederler;

- Etkinliklerin seçilmesi (örn., yarısmak için aynı yetenekteki bir rakibi 
aramak ya da oynamak için daha yüksek ya da daha düsük yetenek seviyesindeki rakipleri seçmek),

- Hedefe ulasmak için harcanan çabanın belirlenmesinde (ne kadar sıklıkla antrenman yaptığı gibi),

- Hedefe ulasmak için harcanacak çabanın siddetinin belirlenmesi (antrenmanda ne kadar istekli olduğu gibi),

- Güçlüklere ya da basarısızlığa göğüs germe (örn., her sey kötü gittiğinde daha çok çalısma ya da bırakma gibi) ( Aktop, 2002) gibi etkileri görülmektedir.

Sporun uluslararası propaganda aracı olarak görülmeye başlanmasından dolayı sportif rekabet artmıştır. $\mathrm{Bu}$ rekabet sonucunda, sporcular motivasyon düzeylerini yüksek tutarak başarılı olmak için daha çok çaba göstermeye başlamışlardır. Aynı zamanda sporcuların rekabet ortamında başarılı olmaya çalışması anksiyete düzeyini arttırabileceği düşünülmektedir. $\mathrm{Bu}$ doğrultuda çalışmada üniversitelerin spor takımlarında oynayan öğrencilerin anksiyete ve başarı motivasyonu düzeylerinin bazı değişkenlere göre anlamlı olup olmadığı, anksiyete ve başarı motivasyonu arasında nasıl bir ilişki olduğu sorularına cevap bulmak amacıyla yapılmıştır.

\section{YÖNTEM}

Çalışma Grubu: Çalışmanın evrenini 20192020 eğitim öğretim güz döneminde Ankara, Pamukkale, Siirt ve Iğdır Üniversitesinin spor takımlarında oynayanlar oluşturmaktadır. Örneklem gurubunu ise evrenden rastgele örneklem seçimi yöntemiyle gönüllü olarak katılan toplam 321 katılımcı oluşturmaktadır.

Veri Toplama Aracı: Katılımcıların demografik özelliklerini tespit etmek için araştırmacılar tarafindan oluşturulan kişisel bilgi formu kullanılmıştır.

Katılımcıların anksiyete düzeyini tespit etmek için Beck (1997) tarafından geliştirilen Türkçe uyarlaması Ulusoy, Şahin ve Ekmen (1997) tarafından yapılan 21 maddeden oluşan ve 4'lü likert olan (yok, hafif, orta, şiddetli) "Beck Anksiyete Ölçeği”" kullanılmıştır. Beck anksiyete ölçeği sübjektif anksiyete
$(1,4,5,7,8,9,10,11,14,15,16,17,19) 13$ madde ve somatik belirtiler $(2,3,6,12,13,18,20,21) 8$ madde olmak üzere iki alt boyuttan oluşmaktadır. Her maddeden 0 ile 3 arası puan alınmaktadır. En yüksek puan 63'tür.

Katılımcıların sporda başarı motivasyonlarını ölçmek için ise Willis (1982) tarafından geliştirilen Türkçe uyarlaması Tiryaki ve Gödelek (1997) tarafindan yapılan "Willis Spora Özgü Başarı Motivasyonu Ölçeği" kullanılmıştır. Spora Özgü Başarı Motivasyonu Ölçeği toplam 40 maddeden oluşan ve maddeleri "hiçbir zaman", "çok az", "bazen", "oldukça fazla" ve "her zaman" şeklinde ifade edilen beşli likert tipindedir. Ölçekte güç gösterme güdüsü $(1,3,5,7,9,10,11,13,21,29,30,35) 12$ madde, başarıya yaklaşma güdüsü(4,6,8,12,16,18,19,20,23,24,26,31,32,3 $3,36,38,39) \quad 17$ madde ve başarısızlıktan kaçma güdüsü $(2,14,15,17,22,25,27,28,34,37,40) \quad 11$ madde ile ölçülmeye çalışılmıştır.

Verilerin analizi: Analizler öncesinde verinin normal dağılıp dağılmadığı kontrol edilmiş ve Kolmogorow-Smirnov normallik testi sonucunda verinin normallik varsayımını karşıladığ 1 belirlenmiştir $\quad(\mathrm{p}>0,05)$. İkili karşılaştırmaların tespiti için T-Testi, ikiden fazla bağımsız değişkenler ile bağımlı değişkenler arasındaki farkın tespiti için ANOVA testi kullanılmıştır. İkiden fazla bağımsız değişkenler ile bağımlı değişkenler arasındaki farkın anlamlılığına ilişkin POSTHOC testlerinden TUKEY testi kullanılmıştır. "Beck Anksiyete" ve "Willis Spora Özgü Başarı Motivasyonu" ölçeği alt boyutları arasındaki ilişkinin tespiti için de Pearson Korelasyon analizi kullanılmıştır. 


\section{BULGULAR}

Tablo 1. Katılımcıların Anksiyete ve Başarı Motivasyonlarının Cinsiyet Değişkenine Göre Karşılaştırılması

\begin{tabular}{|c|c|c|c|c|c|c|}
\hline & Cinsiyet & $\mathrm{N}$ & $\mathrm{X}$ & $\mathrm{Sd}$ & $\mathrm{t}$ & $\mathrm{p}$ \\
\hline \multirow{2}{*}{ Sübjektif } & Erkek & 187 & 26,19 & 319 & $-1,20$ & ,23 \\
\hline & Kadın & 134 & 27,43 & & & \\
\hline \multirow{2}{*}{ Somatik Belirtiler } & Erkek & 187 & 15,98 & & $-2,31$ &, 02 \\
\hline & Kadın & 134 & 17,54 & & & \\
\hline \multirow{2}{*}{ Güç Gösterme Güdüsü } & Erkek & 187 & 43,16 & &,- 06 & ,96 \\
\hline & Kadın & 134 & 43,19 & & & \\
\hline \multirow{2}{*}{ Başarıya Yaklaşma Güdüsü } & Erkek & 187 & 61,95 & &,- 59 &, 56 \\
\hline & Kadın & 134 & 62,56 & & & \\
\hline Başarısızlıktan & Erkek & 187 & 36,64 & & $-2,26$ &, 02 \\
\hline Güdüsü & Kadın & 134 & 38,36 & & & \\
\hline
\end{tabular}

${ }^{*} \mathrm{P}<0,05$

Tabloya 1'e göre Anksiyete ölçeğinin sübjektif alt boyutunda cinsiyet değişkenine göre anlamlı farklılık görülmemiştir. Ancak somatik belirtiler alt boyutunda, kadın öğrencilerin lehine anlamlı farklılık görülmüştür $\mathrm{P}<0,05$. Spora özgü başarı motivasyonu ölçeğinin alt boyutlarından olan başarısızlıktan kaçma güdüsünde, kadın öğrencilerin lehine anlamlı farklılık görülmüştür $\mathrm{P}<0,05$. Fakat güç gösterme güdüsü ile başarıya yaklaşma güdüsü alt boyutlarında anlamlı farklılık görülmemiştir $\mathrm{P}>0,05$.

Tablo 2. Katılımcıların Anksiyete ve Başarı Motivasyonlarının Sınıf Değişkenine Göre Karşılaştırılması

\begin{tabular}{|c|c|c|c|c|c|c|}
\hline & & Kareler & & Kareler & & \\
\hline & & Toplamı & $\mathrm{Sd}$ & Ortalamas1 & $\mathrm{F}$ & $\mathrm{p}$ \\
\hline \multirow{3}{*}{ Sübjektif } & Gruplar aras1 & 352,22 & 4 & 88,06 & 1,07 &, 37 \\
\hline & Gruplar içi & 26114,00 & 318 & 82,12 & & \\
\hline & Toplam & 26466,22 & & & & \\
\hline \multirow{3}{*}{ Somatik Belirtiler } & Gruplar aras1 & 165,40 & & 41,35 & 1,15 &, 33 \\
\hline & Gruplar içi & 11433,49 & & 35,95 & & \\
\hline & Toplam & 11598,89 & & & & \\
\hline \multirow{3}{*}{ Güç Gösterme Güdüsü } & Gruplar aras1 & 221,96 & & 55,49 & 1,43 & ,22 \\
\hline & Gruplar içi & 12284,90 & & 38,63 & & \\
\hline & Total & 12506,87 & & & & \\
\hline \multirow{2}{*}{ Başarıya Yaklaşma Güdüsü } & Gruplar aras1 & 467,23 & & 116,81 & 1,39 &, 24 \\
\hline & Gruplar içi & 26661,46 & & 83,84 & & \\
\hline
\end{tabular}


Yavuz Eroğlu, S., Eroğlu, E. / Üniversite Spor Takımlarında Oynayan Öğrencilerin Anksiyete ve Spora Özgü Başarı Motivasyonu Düzeylerinin İncelenmesi

\begin{tabular}{|c|c|c|c|c|c|c|}
\hline & & Toplam & 27128,69 & & & \\
\hline \multirow{3}{*}{$\begin{array}{l}\text { Başarısızlıktan } \\
\text { Güdüsü }\end{array}$} & \multirow{3}{*}{ Kaçma } & Gruplar arası & 203,26 & 50,81 & 1,11 &, 35 \\
\hline & & Gruplar içi & 14553,08 & 45,76 & & \\
\hline & & Toplam & 14756,34 & & & \\
\hline
\end{tabular}

"P $>0,05$

Tablo 2'ye göre, analiz sonuçları, katılımcıların anksiyete ölçeğinin alt boyutları ile spora özgü başarı motivasyonu ölçeği alt boyutlarının sınıf değişkenine göre anlamlı farklılık göstermemektedir $(\mathrm{p}>0,05)$.

Tablo 3. Katılımcıların Anksiyete ve Başarı Motivasyonlarının Bölüm Değişskenine Göre Karşılaştırılması

\begin{tabular}{|c|c|c|c|c|c|c|}
\hline & & Kareler & & Kareler & & \\
\hline & & Toplamı & $\mathrm{Sd}$ & Ortalamas 1 & $\mathrm{~F}$ & $\mathrm{p}$ \\
\hline & Gruplar aras 1 & 800,98 & 3 & 266,99 & 3,32 &, 02 \\
\hline Subjektif & Gruplar içi & 25665,24 & 319 & 80,46 & & \\
\hline & Toplam & 26466,22 & 322 & & & \\
\hline & Gruplar aras 1 & 460,58 & & 153,53 & 4,40 &, 00 \\
\hline Somatik Belirtiler & Gruplar içi & 11138,31 & & 34,92 & & \\
\hline & Toplam & 11598,89 & & & & \\
\hline & Gruplar aras 1 & 124,69 & & 41,56 & 1,07 &, 36 \\
\hline Güç Gösterme Güdüsü & Gruplar içi & 12382,18 & & 38,82 & & \\
\hline & Toplam & 12506,87 & & & & \\
\hline & Gruplar aras 1 & 344,15 & & 114,72 & 1,37 &, 25 \\
\hline Başarıya Yaklaşma Güdüsü & Gruplar içi & 26784,54 & & 83,96 & & \\
\hline & Toplam & 27128,69 & & & & \\
\hline & Gruplar aras1 & 40,69 & & 13,56 & ,29 &, 83 \\
\hline 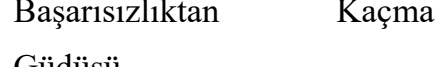 & Gruplar içi & 14715,65 & & 46,13 & & \\
\hline Guadusu & Toplam & 14756,34 & & & & \\
\hline
\end{tabular}

"P $<0,05$

Analiz sonuçları, öğrencilerin anksiyete ölçeğinin subjektif alt boyutunda ve somatik belirtiler alt boyutunda anlamlı farklılık göstermiştir $\mathrm{p}<0,05$. Ancak spora özgü başarı motivasyonu ölçeği alt boyutlarında anlamlı farklılık göstermediği görülmüştür $\mathrm{p}>0,05$. Farkın kaynağına ilişkin yapılan POST-HOC testi sonucu aşağıda verilmiştir.

Tablo 4. Öğrencilerin Anksiyete Ölçeği Alt Boyutlarının Anlamlılığına İlişkin TUKEY Testi Sonuçları

Tukey HSD

(I) bölüm

(J) bölüm

Grup Farkl111kları

S.Hata

$\mathrm{p}$

\begin{tabular}{|c|c|c|c|c|c|}
\hline \multirow{3}{*}{ Sübjektif } & \multirow{3}{*}{ Eğitim } & Antrenörlük & 2,69 & 1,24 &, 14 \\
\hline & & Yöneticilik & 1,88 & 1,35 &, 51 \\
\hline & & Rekreasyon & $-4,86$ & 3,00 &, 37 \\
\hline
\end{tabular}


Yavuz Eroğlu, S., Eroğlu, E. / Üniversite Spor Takımlarında Oynayan Öğrencilerin Anksiyete ve Spora Özgü Başarı Motivasyonu Düzeylerinin İncelenmesi

\begin{tabular}{|c|c|c|c|c|c|}
\hline & \multirow{3}{*}{ Antrenörlük } & Eğitim & $-2,69$ & 1,24 &, 14 \\
\hline & & Yöneticilik &,- 81 & 1,21 & ,91 \\
\hline & & Rekreasyon & $-7,55$ & 2,94 &, 05 \\
\hline & \multirow{3}{*}{ Yöneticilik } & Eğitim & $-1,88$ & 1,35 &, 51 \\
\hline & & Antrenörlük &, 81 & 1,21 & ,91 \\
\hline & & Rekreasyon & $-6,74$ & 2,99 &, 11 \\
\hline & \multirow{3}{*}{ Rekreasyon } & Eğitim & 4,86 & 3,00 &, 37 \\
\hline & & Antrenörlük & 7,55 & 2,94 &, 05 \\
\hline & & Yöneticilik & 6,74 & 2,99 &, 11 \\
\hline \multirow{12}{*}{ Somatik Belirtiler } & \multirow{3}{*}{ Eğitim } & Antrenörlük & 1,92 &, 82 & ,09 \\
\hline & & Yöneticilik & ,48 &, 89 & ,95 \\
\hline & & Rekreasyon & $-3,94$ & 1,98 &, 19 \\
\hline & \multirow{3}{*}{ Antrenörlük } & Eğitim & $-1,92$ &, 82 & ,09 \\
\hline & & Yöneticilik & $-1,45$ &, 80 &, 27 \\
\hline & & Rekreasyon & $-5,86^{*}$ & 1,94 &, 01 \\
\hline & \multirow{3}{*}{ Yöneticilik } & Eğitim &,- 48 &, 89 & ,95 \\
\hline & & Antrenörlük & 1,45 &, 80 &, 27 \\
\hline & & Rekreasyon & $-4,41$ & 1,97 &, 11 \\
\hline & \multirow{3}{*}{ Rekreasyon } & Eğitim & 3,94 & 1,98 &, 19 \\
\hline & & Antrenörlük & $5,86^{*}$ & 1,94 &, 01 \\
\hline & & Yöneticilik & 4,41 & 1,97 &, 11 \\
\hline
\end{tabular}

${ }^{*} \mathrm{P}<0,05$

Tablo 4'e göre, rekreasyon ve antrenörlük bölümü öğrencileri arasında anlamlı farlılık olduğu görülmüsstür. Sıra ortalamaları dikkate alındığında rekreasyon bölümü öğrencilerinin diğer bölüm öğrencilerine göre anlamlı olduğu görülmüş̧ür $\mathrm{p}<0,05$.

Tablo 5. Anksiyete ve Sporda Başarı Motivasyonu Ölçeklerinin Alt Boyutları Arasındaki Korelasyon Analizi Sonuçları

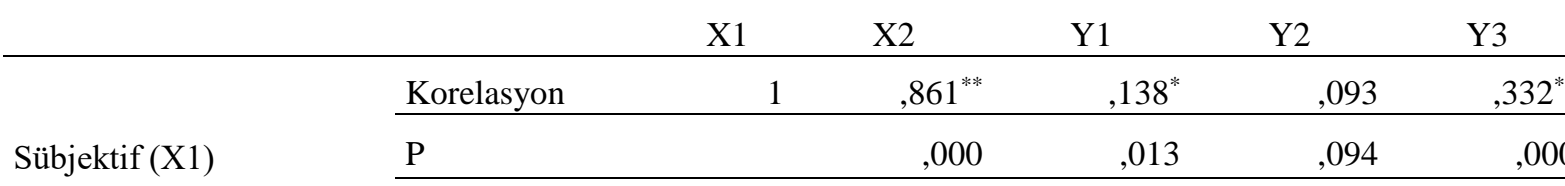

\begin{tabular}{llrrrr}
\hline & Korelasyon & 1 &, $143^{* *}$ &, 069 &, $319^{* *}$ \\
\cline { 2 - 6 } Somatik Belirtiler $(X 2)$ & $\mathrm{p}$ &, 010 &, 217 &, 000 \\
\cline { 2 - 6 }
\end{tabular}

\begin{tabular}{lllrrr}
\hline Güç Gösterme Güdüsü Korelasyon & 1 &, $752^{* *}$ &, $574^{* *}$ \\
\cline { 2 - 5 } & &, 000 &, 000 \\
\hline
\end{tabular}

\begin{tabular}{|c|c|c|c|}
\hline Başarıya & Yaklașma Korelasyon & 1 &, $595^{* *}$ \\
\hline
\end{tabular}


Yavuz Eroğlu, S., Eroğlu, E. / Üniversite Spor Takımlarında Oynayan Öğrencilerin Anksiyete ve Spora Özgü Başarı Motivasyonu Düzeylerinin İncelenmesi

Güdüsü (Y2)

$\underline{\mathrm{p}}$

$\begin{array}{lllll}\text { Başarısızlıktan } & \text { Kaçma } & \text { Korelasyon } & 1 \\ \text { Güdüsü (Y3) } & \mathrm{P} & \end{array}$

$* \mathrm{p}<0,05$

Tablo 5'e göre, anksiyete ve sporda başarı motivasyonu ölçeklerinin alt boyutları arasındaki korelasyon ilişkisinde sübjektif ve somatik belirtiler ile güç gösterme ve başarısızlıktan kaçma güdüsünde düşük düzeyde pozitif ve anlamlı bir ilişki olduğu görülmüştür. Ancak sübjektif ve somatik belirtiler ile başarıya yaklaşma güdüsünde, düşük düzeyde pozitif ve anlamlı bir ilişki olmadığı görülmüştür.

\section{TARTIŞMA ve SONUÇ}

Çalışmamızın bulguları doğrultusunda konumuzla ilgili ya da yakın ilgisi olan kaynaklara ulaşılmıştır. Yapmış olduğumuz çalışmada ele aldığımız anksiyete ve başarı motivasyonu alt boyutlarının cinsiyet, bölüm ve sınıf değişkenlerine göre farklılaşıp farklılaşmadığına baktığımızda cinsiyet değişkeninde anksiyete ölçeğinin somatik belirtiler alt boyutunda, kadın katılımcıların lehine anlamlı farklılık görülmüştür $\mathrm{P}<0,05$. Spora özgü başarı motivasyonu ölçeğinin alt boyutlarından olan başarısızlıktan kaçma güdüsünde, kadın katılımcıların lehine anlamlı farkl11ı görülmüştür $\quad \mathrm{P}<0,05$. Sinıf değişkenine göre anlamlı farklılık görülmemiştir. Bölüm değişkenine göre rekreasyon ve antrenörlük bölümünde okuyup spor takımlarında oynayan öğrenciler arasında anlamlı farlılık olduğu görülmüştür. Sıra ortalamaları dikkate alındığında rekreasyon bölümü öğrencilerinin diğer bölüm öğrencilerine göre anlamlı olduğu görülmüştür.

Somatik belirtiler kişilerin yorgunluk ya da ağrı gibi fiziksel belirtiler karşısında aşırı endişe duymalarıdır. Ayrıca günlük yaşamına etki eden bir belirtidir. Kadınların erkeklere göre sorumluluklarının daha fazla olması, daha fazla duygusal yapıya sahip olmaları ve sosyal hayatta daha az var olmaları bazı kaygı durumlarını da fazla yaşamalarına sebep olabilir. Depresyonun ülkemizde son y1llarda ciddi artış gösterdiğine ilişkin önemli veriler bulunmaktadır. Ayrıca bu hastalığın cinsiyetler bağlamındaki dağılımı incelendiğinde kadınlarla erkekler arasında gözlemlenen farklılıkların sosyolojik bir nitelik taşıdığı görülmektedir. İstatistikî çalışmalara bakıldığında kadınlarda ruhsal hastalıkların görülme oranı, erkeklerde görülen ruhsal hastalık oranlarının yaklaşık iki katıdır. Yine, depresyona giren veya yaşam boyunca bu hastalığa yakalanma riski olan kadınların oranının erkeklerinkinden iki kat daha fazla olduğu bilinmektedir (Çelikkol, 2001: 217). Böyle bir durumun olması dolaylı olarak başarıdan kaçma güdüsünü de etkilemektedir. Diğer bir bulguya göre ise rekreasyon bölümü okuyanların kendilerine ayırdıkları boş zamanı kaliteli kullanabilme olanağ1 bulduklarından rekabet duygusu yaşadıkları zaman duygularını kontrol etmede sıkıntı yaşayabilecekleri düşüncesi ile çalışmamızda böyle farkların çıkması beklenen bir durum olarak görülmektedir. Literatürde yer alan ve çalışmamıza benzer ya da tezat olduğu görülen çalışmalar aşağıda verilmiştir.

Aktas ve arkadaşlarının 2006 yılında Profesyonel Basketbolcularda Spora Özgü Başarı Motivasyon Düzeyinin Cinsiyetler Açısından Karşılaştırılması adlı araştırmalarında, erkekler ve kadınlar arasında güç gösterme güdüsü ve basaryya yaklasma güdüsü açısından istatistiksel olarak anlamlı bir fark bulmuşken, başarısızlıktan kaçınma güdüsü açısından istatistiksel olarak anlamlı bir farka rastlamamışlardır.

Engür tarafından 2002 yılında yapılan Elit Sporcularda Başarı Motivasyonunun, Durumluk Kaygı Düzeylerine Etkisi konulu araştırma yapmıştır. Cinsiyete göre durumluk 
kayg1 düzeyi arasında istatistiksel olarak anlamlı bir fark bulunamamıştır. Ancak, araştırmaya katılan kadın sporcuların başarı güdülenmesinin "başarısızlıktan kaçınma güdüsü" alt ölçeğine ilişkin ortalama puanları erkeklerin ortalama puanlarından istatistiksel olarak anlamlı bir şekilde yüksek bulunmuş.

Er ve arkadaşlarının 2003'de Sporda Başarı Motivasyonunun Cinsiyetler Açısından Analizi adlı araştırmasında kadınların ve erkeklerin güç gösterme güdüsünün bir birlerinden çok farklı olduğunu, başarıya yaklaşma güdüsünün her iki cinste de aynı olduğunu, başarısızlıktan kaçınma güdüsünün ise yine her iki cinste da aynı olduğunu tespit etmişlerdir.

Kaya ve Şahin'in (2006) yapmış olduğu Rekreasyon Faaliyetlerinin İlköğretim Okulu Öğrencilerinin Durumluluk Ve Sürekli Kayg1 Düzeyleri Üzerine Etkileri adlı çalışmada rekreasyon faaliyetleri sonunda kız ve erkek öğrencilerin sürekli kaygı düzeyinde anlamlı bir azalmanın olduğu görülmüştür.

Aktop ve Erman (2002), Takım Ve Bireysel Sporcuların Başarı Motivasyonu Benlik Saygısı Ve Sürekli Kaygı Düzeylerinin Karşılaştırılması ile ilgili çalışmasında takım ve bireysel sporlar ile uğraşan sporcuların spora özgü başarı motivasyonun alt boyutlarında anlamlı farklılık tespit edilmemiştir (Türkmen, 2005).

Yanar, Kırandı ve Can'ın (207) yapmış olduğu Tenis Ve Badminton Sporcularının Sporcu Kimlik Algısı Ve Başarı Motivasyon Düzeyleri Arasındaki Farklılıkların İncelemesi adlı çalışmada sporda başarı motivasyonunun kadınlar lehine olduğu tespit edilmiştir.

Yalçınsoy'un (2017) yapmış olduğu Yaşam Doyumu, Kaygı Ve Motivasyon İlişkisi İle İlgili Üniversite Gençliğine Yönelik Bir Araştırma adlı çalışmada cinsiyet değişkeninde erkekler lehine anlamlı sonuçlara ulaşılmıştır. Sınıf değişkeninde de 1. Ve 2. Sinıflar lehine anlamlı sonuçlar bulunmuştur.

Üniversite spor takımlarında oynayan öğrencileri ele aldığımız bu çalışmada farklı sonuçların yer alması örneklem grubunun farklılı̆̆ından ve yaşanılan yer farkından kaynaklandığı söylenebilir. Ayrıca benzer çalışmalar branş, fakülte gibi farklı değişkenler kullanılarak yapılması önerilebilir.

\section{KAYNAKÇA}

Aktaş, Z., Çobanoğlu, G., Yazıcılar, İ., ve Er, N. (2006). Profesyonel Basketbolcularda Spora Özgü Başarı Motivasyon Düzeyinin Cinsiyetler Açısından Karşılaştırılması. SPORMETRE Beden Eğitimi ve Spor Bilimleri Dergisi; IV (2): 55-59.

Aktop, A. (2002). Spora Özgü Basarı Motivasyonu ile Psikolojik Ve yapısal Özellikler Arasındaki İliskinin Incelenmesi. Yüksek Lisans Tezi, Akdeniz Üniversitesi, Sağllk Bilimleri Enstitüsü, Beden Eğitimi ve Spor Öğretmenliği Anabilim Dalı, Antalya.

Baltaş, Z., ve Baltaş, A. (1992). Stres ve Basa Çıkma Yolları, Altıncı Basım, İstanbul, Remzi Kitabevi.

Cüceloğlu, D. (1991). İnsan ve Davranışl, İstanbul, Remzi Kitabevi.

Çelikkol, Ahmet, (2001), Çağdaş İş Yaşamında Ruh Sağlığı, Alfa Yayınları, İstanbul.

Dubovsky, S. L. (1990). Understanding and Treating Depression in Anxious Patients, Journal of Clinical Psychiatry, 3-8.

Engür, M. (2002). Elit Sporcularda Başart Motivasyonunun, Durumluluk Kaygl Düzeyleri Üzerine Etkisi, Yüksek Lisans Tezi, Ege Üniversitesi, Sağlık Bilimleri Enstitüsü, İzmir.

Er, N. ve Ark. (2003). Sporda Başarı Motivasyonunun Cinsiyetler Açısından Analizi, Beden Eğitimi ve Sporda Sosyal Alanlar Kongresi Bildiriler Kitabl, Gazi Üniversitesi Beden Eğitimi ve Spor Yüksek Okulu, Ankara, s: 459-460

Horst, D. E. M. (1976). Sportphysiologie, Tropon Werke Köln- München.

İkizler, C., ve Karagözoğlu, C. (1997). Sporda Başarının Psikolojisi, İstanbul, Alfa Basım Yayım Dağıtım.

Kaya, Y., Şahin, T. (2006). Rekreasyon Faaliyetlerinin İlköğretim Okulu Ögrencilerinin Durumluluk Ve Sürekli 
Kaygı Düzeyleri Üzerine Etkileri, Gazi Beden Eøitimi ve Spor Bilimleri Dergisi (Gazi BESBD), XI (2006), $3: 23$ - 34

Rachman, S. (1998). Anxiety, Psychology Press, UK, p: 3.

Reyhan, S., Yarayan, Y.E. (2017). Beden Eğitimi ve Spor Yüksekokulu Öğrencileri ile Diğer Fakülte ve Yüksekokullarda Öğrenim Gören Üniversite Öğrencilerinin Attlganlık Düzeylerinin Karşılaş̧tırılması, Sosyal Bilimler Enstitüsü Dergisi Journal of Social Sciences Institute, Say1 10

Taparlı, T. Z. (2004). Yoğun Bakım Ünitelerinde Çalışan Hemşirelerin Anksiyete Düzeyleri ve Nedenlerinin Belirlenmesi. Yüksek Lisans Tezi Çukurova Üniversitesi Sağlık Bilimleri Enstitüsü

Tiryaki, S. (2000). Spor Psikolojisi, Kuramlar ve Uygulama, Mersin, Eylül Kitap ve Yayınevi.

Turhan, M. (2009). Profesyonel Futbolcularda Depresyon Düzeyi, Anksiyete Düzeyi ve Kişilik Özellikleri ile Sporda Başarı Motivasyonu Arasındaki İlişkinin İncelenmesi, Yüksek Lisans Tezi, İstanbul Maltepe Üniversitesi, Sosyal Bilimler Enstitüsü. İstanbul

Türkmen, M. (2005). Profesyonel ve Amatör Erkek Futbolcuların Sporda Başarı Motivasyonu ve Başarı Gereksinimi Düzeylerini Belirlemek. Celal Bayar Ü. Sağlık Bilimleri Enstitüsü, Yüksek Lisans Tezi, İzmir

Yanar, Ş., Kırandı, Ö., Can, Y. (2017). Tenis ve Badminton Sporcularının Sporcu Kimlik Algısı ve Başarı Motivasyon Düzeyleri Arasındaki Farklıl1kların İncelemesi, Spor Eğitim Dergisi, 2017, Cilt 1, Say1 1, 5158.

Yavilioğlu, C. (2000). Ekonomik Kalkınma ve Motivasyon Arasındaki İlişki. Cumhuriyet Üniversitesi, Iktisadi ve İdari Bilimler Dergisi, Cilt 2, Say12. Sivas.

Yalçınsoy, A. (2017). Yaşam Doyumu, Kaygı Ve Motivasyon İlişkisi İle İlgili Üniversite Gençliğine Yönelik Bir Araştırma, Kesit Akademi Dergisi, Yıl: 3, Sayı: 10, Aralık 2017, s. 422-434 